\title{
Structural analyses of Shigella invasion proteins reveals non-conserved; intrinsically unstructured regions
}

\author{
Santanu Chakrabarti ${ }^{1, *}$, Sayak Ganguli ${ }^{2, * *}$ \\ ${ }^{1}$ Department of Zoology, Acharya Prafulla Chandra Roy Government College, \\ Silguri 734 010, WB, India \\ ${ }^{2}$ DBT Centre for Bioinformatics, Presidency University, Kolkata 700073, WB, India \\ *,**E-mial address: scwbes@gmail.com , sayakbif@yahoo.com
}

\begin{abstract}
Shigella is one of the most common bacterial pathogens that are isolated from patients with diarrhea. Various attempts are being made worldwide with encouraging observations; still the emergence of multidrug-resistant Shigella strains and a continuous high disease incidence imply that shigellosis is an unsolved global health problem which can probably be solved only by developing a proper vaccine and a vaccine regime for the disease. The need of the hour is to foster the development of an effective vaccine which should not only serve to improve hygiene but also should be able to curb infections by the pathogen. This goal can only be achieved by gaining proper detailed knowledge underlying Shigella pathogenesis. The analyses of the Shigella invasion proteins which have been long been targeted to be potential candidate vaccines remains an open ended problem and forms the core of this present computational study which identifies the fact that long regions in the structure of the proteins are disordered having no distinct structural conformation; multiple alignments however, did not show any conserved stretches in the disordered regions. The results probably explain the ability of these proteins to interact with multiple cellular proteins and perform a diverse array of functions leading to successful pathogenesis.
\end{abstract}

Keywords: Invasion proteins; intrinsically unstructured proteins; moonlighting; Kyle - Doolittle scale; Disordered region; functional promiscuity

\section{INTRODUCTION}

Among the first group of proteins secreted by the Shigella spp. type III secretion system, are the dominant immunogenic invasion plasmid antigens IpaA to IpaD (Hromockyj et.al. 1989; Yang et.al. 2007) of which IpaB, IpaC and Ipa D have been identified to be the key virulence factors. Invasion of epithelial cells by Shigella is an essential pathogenic feature of bacillary dysentery. Several workers have indicated that the prerequisite for Shigella internalization is the successful delivery of a viral load of a set of effector proteins through the type III secretion system of the bacteria into the epithelial cells of the host. This package is consisted of the Shigella invasion proteins such as IpaA, IpaB, IpaC, IpaD, IpgD and 
virulence proteins such as VirA (Allaoui et al., 1993a; Ménard et al., 1993, 1994; Uchiya et al., 1995; Tran Van Nhieu et al., 1997; Tran Van Nhieu and Sansonetti, 1999). Though we have much to learn and envisage regarding the precise mechanisms of invasion recent studies have indicated that IpaA and IpaC once inside the host are capable of modulating dynamics of actin filaments as well as signal transduction pathways which are needed for the survival of the pathogen. (Tran Van Nhieu et al., 1997, 1999; Bourdet-Sicard et al., 1999; Tran Van Nhieu and Sansonetti, 1999).

Thus Shigella invasion proteins may serve as prime targets for vaccine development since they are an essential part of the triggering cascade. Their key functions are provided in Table 1 (Yoshida, 2006).

Table 1. Invasion plasmid antigens of Shigella and their key functions. (Yoshida, 2006). This table provides a brief idea about the multitasking abilities of the Shigella invasion proteins during their role in the pathogenesis.

\begin{tabular}{|c|c|}
\hline IpaA & $\begin{array}{r}\text { Increasing invasion, actin cytoskeleton rearrangements, disassembly of } \\
\text { cell-matrix adherence }\end{array}$ \\
\hline IpaB & $\begin{array}{r}\text { Control of type III secretion, formation of Translocon, mediating } \\
\text { phagosome escape, macrophage apoptosis }\end{array}$ \\
\hline IpaC & $\begin{array}{r}\text { Formation of Translocon and filopodium, mediating phagosome } \\
\text { escape, disrupting the EC tight junctions }\end{array}$ \\
\hline IpaD & Type III secretion control, membrane insertion of translocon \\
\hline
\end{tabular}

The present computational study tried to identify the fact that long regions in the structure of the Ipa proteins of Shigella are disordered i.e. having no distinct structural conformation.

\section{MATERIALS AND METHOD}

Uversky et al. (2000) has defined the mean net charge, $\langle\mathrm{R}\rangle$, as the absolute value of the difference between the numbers of positively and negatively charged residues at $\mathrm{pH} 7.0$, divided by the total residue number, and the mean hydrophobicity, $\langle\mathrm{H}\rangle$, as the sum of all residue hydrophobicities, divided by the total number of residues, using the Kyte/Doolittle scale (Kyte and Doolittle, 1982), rescaled to a range of 0-1. Using the same algorithm, the threshold used for the analyses was kept using mean hydrophobicity at -1.16 and mean net charge at 2.785 .

The FoldIndex equation was used as standard and all positive values indicated residues with less potential to get folded while negative values indicated propensity for unstructuredness. The results were then verified using established programs such as Fold Index (Prilusky 2005) and PONDR - Fit (Xue 2010) programs. A multiple sequence alignment followed by phylogenetic tree was generated using MUSCLE with standard input parameters. 


\section{RESULTS AND DISCUSSION}

All four major Shigella Invasion proteins displayed large regions of unstructuredness according to our calculations (Fig 1). The verification of the results by the established prediction programs such as PONDR- FIT (Fig. 2) and Fold Index (Fig. 3) also showed similar degrees of unstructuredness in the Shigella invasion proteins.

Fig. 1. Predicted unstructuredness in the Shigella invasion proteins. (Amino acids in capital letters indicate disordered residues as predicted).

\begin{tabular}{|c|c|c|}
\hline $\begin{array}{l}\text { Protein } \\
\text { Name }\end{array}$ & Disorder & Residues \\
\hline IpaA & $\begin{array}{l}1-59,63-90 \\
101-120 \\
124-174 \\
193-207 \\
214-239 \\
257-356 \\
374-499 \\
511-576 \\
584-633\end{array}$ & $\begin{array}{l}\text { MHNVNNTQAP TFLYKATSPS STEYSELKSK ISDIHSSQTS LKTPASVSEK ENFATSFNQk cIDFLFSSSG KEDVLRSIYS } \\
\text { NSMNAYAKSE ilefsnvlys LVHQNDLNFE NEKGLQKIVA qysELIKDK LSQDSAFGPW SAKNKKLHQL RQNIEHRLAL } \\
\text { LAQQHTSGEA LSLGqkIlnt evssfiknni laELKLSNET VSSLKLDdlv daqAKLAFDS LRNQRKNTID SKGFGIGKLs } \\
\text { rdlntvavfp ellrkvLNDI LEDIKDSHPI QDGLPTPPED MPDGGPTPGA NEKTSQPVIH YHINNDNRTY DNRVFDNRVY } \\
\text { DNSYHENPEN DAQSPTSQTN DLLSRNGNSL LNPQRAlvqk vtsvIphsis davQTFANNS ALEKVFNHTP DNSDGIGSDL } \\
\text { LTSSSQERST NNSLSRGHRP LNIQNSSTTP PLHPEGVTSS NDNSSDTTKS SASLSHRVAS QINKFNSNTD SKVLQTDFLS } \\
\text { RNGDTYLTRE TIFEASKKVt nsIsnlisli GTKSGTQERE LQEKSKDITK STTEHRINNK LKVTDANTIN YVTETNADTI } \\
\text { DKNHAIYEKA KEVSSAlskv IskIDDTSAE LLTDDISDLK NNNDITAENN NIYKAAKDVT TSLSKVLKNI NKD }\end{array}$ \\
\hline IpaB & $\begin{array}{l}1-10,22-33 \\
46-74,97- \\
243,259- \\
305,387- \\
393,448- \\
460,521- \\
546,559- \\
571\end{array}$ & $\begin{array}{l}\text { MHNVSTTTTG fplakilast eLGDNTIQAA NDAanklfsl tiadITANQN INTTNAHSTS NILIPELKAP KSLNassqlt Ilignliqil } \\
\text { geksItALTN KITAWKSQQQ ARQQKNLEFS DKINTLLSET EGLTRDYEKQ INKLKNADSK IKDLENKINQ IQTRLSELDP } \\
\text { ESPEKKKLSR EEIQLTIKKD AAVKDRTLIE QKTLSIHSKL TDKSMQLEK IDSFSAFSNT ASAEQLSTQQ KSLtglasvt } \\
\text { qlmatfiqLV GKNNEESLKN DLALFQSLQE SRKTEMERKS DEYAAEVRKA EELNRvmgcv gkilgallti vsvvaaafsg } \\
\text { gaslalaavg lalmvtdaiv qaatgnsfme qalnpimkav ieplikIlsd aftkmIEGLG VDSkkakmig silgaiagal vlvaavvlva } \\
\text { tvgkqaaakl aenigkiigk tltdlipKFL KNFSSQLDDL itnavarlnk flgaagdevi skqiisthln qavllgesvn satqaggsva } \\
\text { savfqnsast NLADLTLSKY QVEQLSKYIS EAIEKFgqlq eviadllaSM SNSQANRTDV Akailqqtta }\end{array}$ \\
\hline IpaC & $\begin{array}{l}\text { Disorder } 1- \\
40,47-98 \\
141-145 \\
171-284 \\
291-335 \\
343-361\end{array}$ & $\begin{array}{l}\text { MEIQNTKPTQ ILYTDISTKQ TQSSSETQKS QNYQQIAAHI plnvgkNPVL TITLNDDQLL KLSEQVQHDS EIIARLTDKK } \\
\text { MKDLSEMSHT LTPENTLDis sIssnavsli isvavllsal rtaetklgsq Isliafdatk SAAENivrqg laalsssitg avtqvgitgi } \\
\text { GAKKTHSGIS DQKGALRKNL ATAQSLEKEL AGSKLGLNKQ IDTNITSPQT NSSTKFLGKN KLAPDNISLS TEHKTSLSSP } \\
\text { DISLQDKIDT QRRTYELNTL SAQQKQNIGR ATMEtsavag NISTSGGRYA SALEEEEQLI SQASSKQAEE ASQVSKEASQ } \\
\text { ATNQLiqkII niIDSINQSK NSTASQIAGN Ira }\end{array}$ \\
\hline IpaD & $\begin{array}{l}1-164, \\
179-307\end{array}$ & $\begin{array}{l}\text { MNITTLTNSI STSSFSPNNT NGSSTETVNS DIKTTTSSHP VSSLTMLNDT LHNIRTTNQA LKKDLSQKTL TKTSLEEIAL } \\
\text { HSSQISMDVN KSAQLLDILS KKEYPINKDA RELLHSAPKE AELDGYEMIS HRELWDKIAK SINNINEQYL KVYEHAVSSY } \\
\text { TQMY qdfsav Isslagwi SP GGNDGNSVKL QVKSLKDELT KLKEKYKDKP LYPANNTVSK EQANKWLTEL GGTIGKVSEK } \\
\text { NGGYVVNINM TPIDNTLKSL DNLGGNGEV LDNAKYQAWN AGFSAEDETM KNNLQTLVQK YSNANSI fdn } \\
\text { Ivkvlsstis sctdtdkIfl hf }\end{array}$ \\
\hline
\end{tabular}

The figure provides insights on the exact residues that are predicted to be in the intrinsically disordered region of the various Shigella invasion proteins.

Ganguli et.al. (2011) have reported the significance of structural analyses in developing an immuno-prophylactic measure such as vaccine identification and design in their works. Over the years numerous evidences has accumulated that many important proteins, in whole or in part, is unstructured in their native state (Amitai et.al. 2007).

Such proteins have been referred to as intrinsically unstructured proteins and rather than folding into a single, stable, 3D structure, these protein members exist as a conglomeration of rapidly changing conformations which are interchangeable and often appear like the denatured states of ordered proteins (Ma 1999; Tsai et.al. 1999; 2001, 2009). 


\section{Intrinsically Unstructured Regions of Shigella Invasion Proteins}
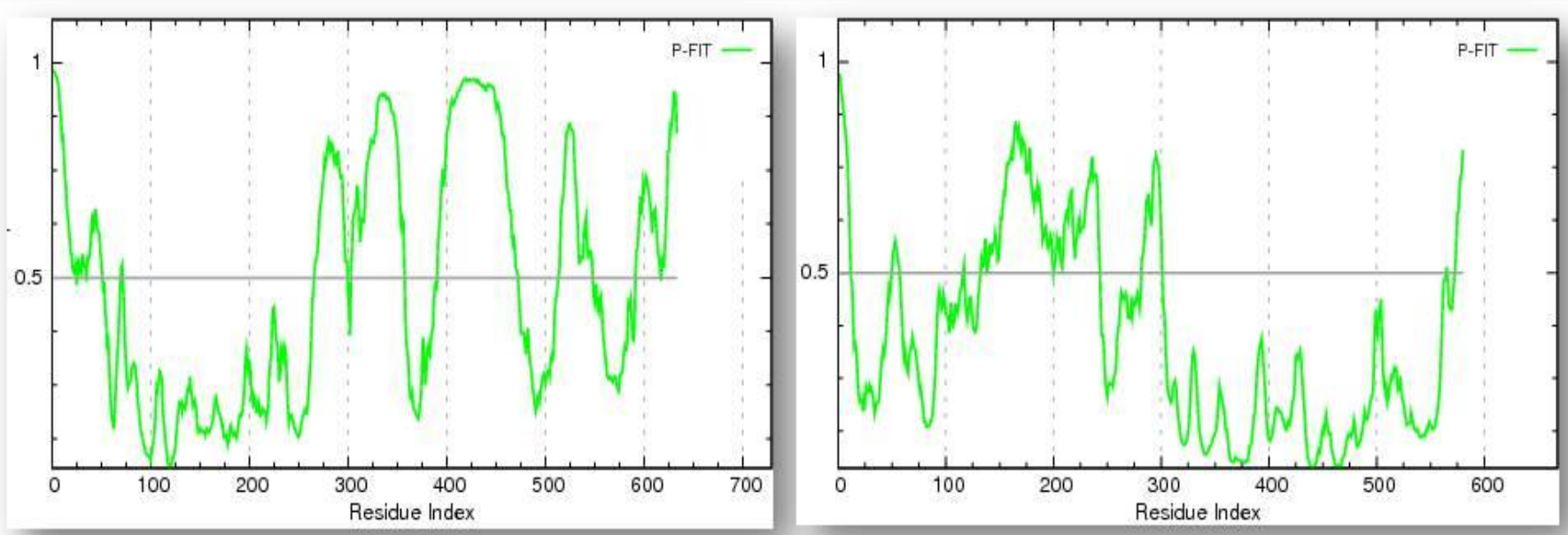

Ipa-A


Ipa-C

Ipa-D

Fig. 2. Prediction of disordered region by PONDR - FIT ( 0.5 threshold) The above figure provides a graphical overview regarding the number of intrinsically disordered residues present in the four Shigella invasion proteins used in the study. The threshold used for analyses is 0.5 which is considered to be standard for bacterial systems.

Though most of these proteins have been reported to lack stable secondary or tertiary structural conformations, yet many of them have been implicated in crucial role plays in regulatory cellular events such as transcription regulation, mRNA processing, DNA condensation along with differentiation and apoptosis.

Some workers believe that there lies an intricate network of proteins which possess no definite structural conformation in part or in whole and functional promiscuity. Such proteins have been referred to as moonlighting proteins (Tompa 2005; Hernandez et.al. 2012) and it may be envisaged that the functional multiplicity may be as a result of the disordered regions. 


\section{Intrinsically Unstructured Regions in the Shigella Imasion Proteins}

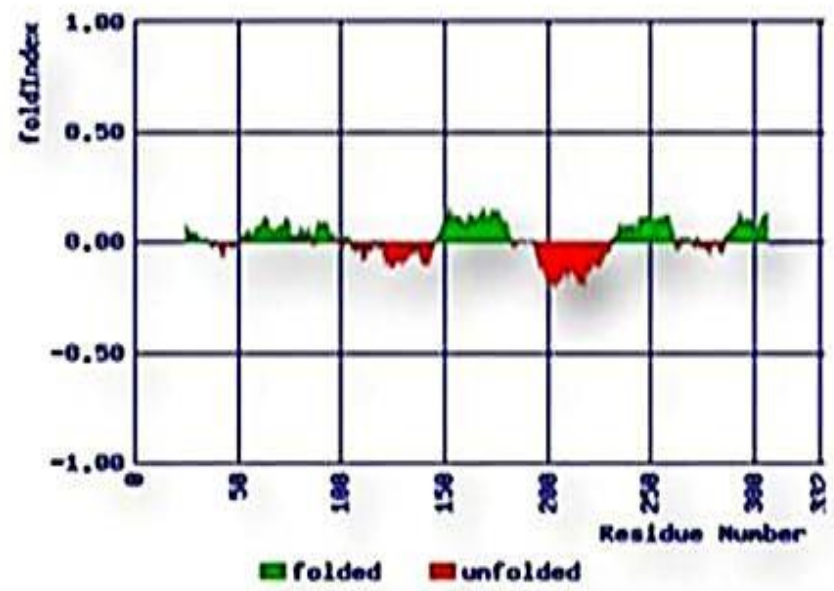

Ipa-A

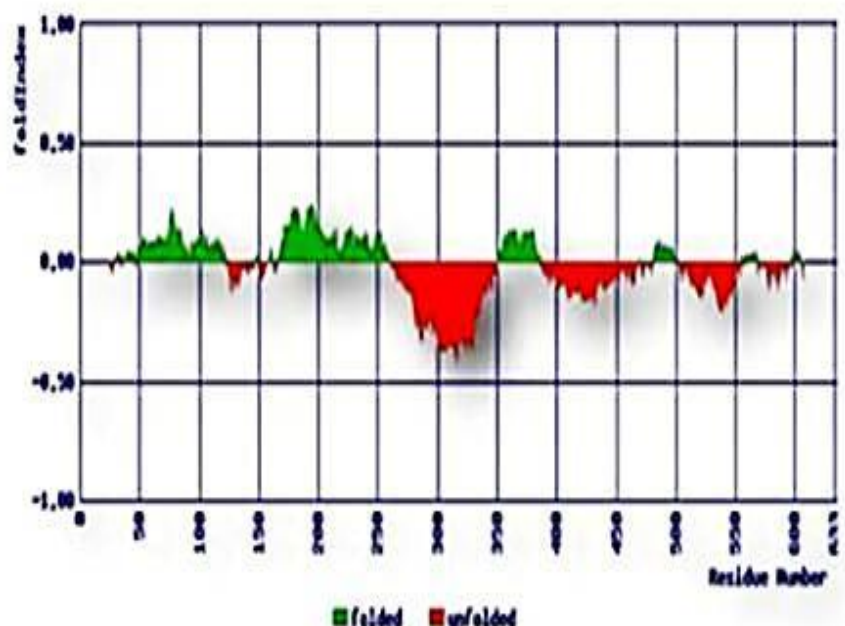

Ipa-C

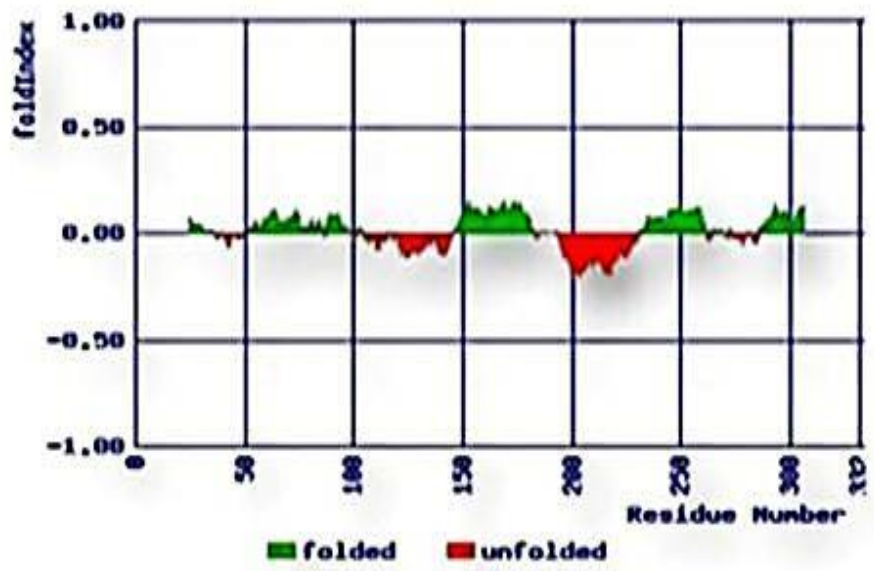

Ipa-B

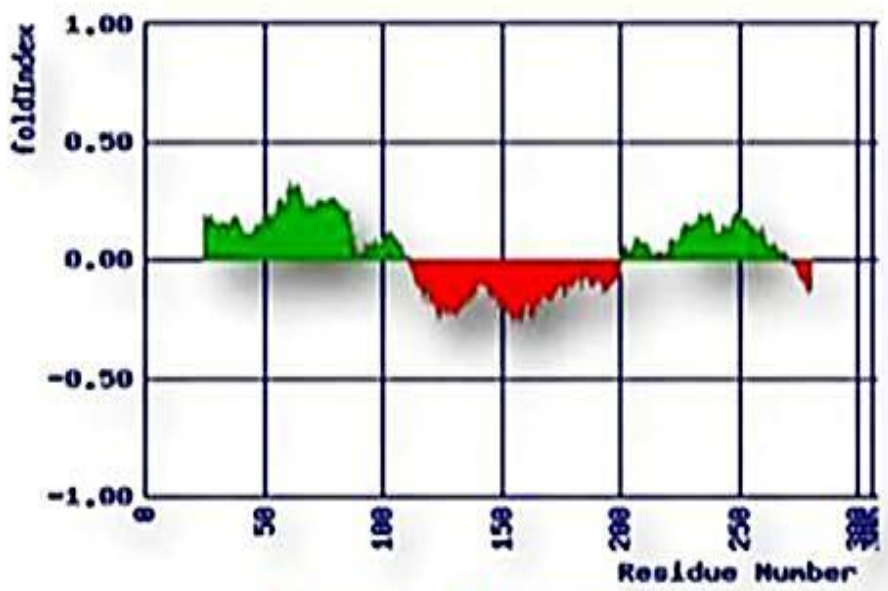

Golded $\square$ unfolded

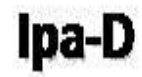

Fig. 3. Prediction of disordered region (indicated in red) by FOLD INDEX.

The above figure provides a graphical overview regarding the number of intrinsically disordered residues present in the four Shigella invasion proteins used in the study. The threshold used for analyses is 0.5 which is considered to be standard for bacterial systems. 
The needle part of the Supramolecular structure of the Shigella type III secretion machinery has showed that it is changeable in length and essential for delivery of other effectors in Shigella invasion related pathomechanisms (Koichi Tamano et al, 2000).

The identification of multiple residues exhibiting lack of proper secondary structure or disorderedness in the four major Shigella invasion proteins possibly sheds light on the fact as to how all of these proteins perform more than one function in the pathogenesis cascade of Shigella. Whether they can be referred to as moonlighting proteins is a case for experimental establishment in control environments; however, it can be safely concluded that the intrinsic disordered regions of the four Shigella proteins under study play major role in the pathogenesis leading to functional diversity (Carayol et.al. 2013). The phylogenetic tree (fig 4) showed that IpaA and IpaD form a single sister group while IpaC and IpaB tend to evolve in a parallel path.

Fig. 4. Phylogenetic relationships among the invasion proteins of Shigella.

\begin{tabular}{|l|l}
\hline & 0.43212 \\
\hline 0.03511 & 0.42933 \\
\hline & 0.44330 \\
\hline & 0.40794 \\
\hline
\end{tabular}

gi|384546108|ref\}YP_005712020. gi|242200048/gblACS88189.1] gi|32307018|gb|AAP78988.1| gi|384546107|ref|YP_005712019.

The phylogenetic tree provides an insight on the interrelationship amongst the four invasion proteins used for this study along with their evolutionary distances.

\section{CONCLUSION}

The identification of disordered regions in the Shigella invasion proteins provide insights to important structural dynamics of invasion proteins secreted by the type two secretion system of the bacterial pathogens. Most pathogens have been reported.

\section{Acknowledgement}

The authors acknowledge the DBT - BTBI scheme for provision of funds used to maintain the facility.

\section{References}

[1] Amitai G., Gupta R. D., Tawfik D. S., HFSPJ 1 (2007) 67-78.

[2] Buchrieser C., P. Glaser, C. Rusniok, H. Nedjari, H. D'Hauteville, F. Kunst, P. Sansonetti, C. Parsot, Mol. Microbiol. 38 (2000) 760-771.

[3] Carayol N., Tran Van Nhieu G., Current Opinion in Microbiology 16(1) (2013) 32-37.

[4] Choudhari S. P., et al., Protein Sci. 22(5) (2013) 666-670.

[5] Ganguli S., Gupta D., Datta A., Int. Jour. of Comp. Biol. (2)1 (2011) 38-40.

[6] Hernández S., et al., J. Proteomics Bioinform. 5 (2012) 262-264.

[7] Hromockyj A. E., A. T. Maurelli, Infect. Immun. 57 (1989) 2963-2970

[8] Kyte J., Doolittle R. F., J. Mol. Biol. 157(1) (1982) 105-132. 
[9] Ma B., Kumar S., Tsai C. J., Nussinov R., Protein Eng. 12 (1999) 713-720.

[10] Nandi T., Gupta S., Ganguli S., Datta A., International Journal of Biology, Pharmacy and Allied Sciences 1(9) (2012) 1 -2.

[11] Prilusky J., et al., Bioinformatics 21(16) (2005) 3435-8.

[12] Tompa P, Szász C, Buday L., Trends Biochem Sci. 30 (2005) 484-489.

[13] Tsai C. J., Ma B., Nussinov R., Proc Natl Acad Sci 96 (1999) 9970-9972.

[14] Tsai C. J., Ma B., Nussinov R., Trends Biochem Sci. 34 (2009) 594-600.

[15] Tsai C. J., Ma B., Sham Y. Y., Kumar S., Nussinov R., Proteins 44 (2001) 418-427.

[16] Uversky V. N., et al., Proteins 41 (2000) 415-427.

[17] Xue B., R. L. DunBrack, R.W. Williams, A. K. Dunker, V. N. Uversky, Biochem. Biophys. Acta 1804(4) (2010) 996-1010.

[18] Yang J., et al., J. Mol. Evol. 64 (2007) 71-79.

[19] Yoshida S., et al., Science 314 (2006) 985-989.

[20] Allaoui A., Ménard R., Sansonetti P. J., Parsot C. (1993a), Infect. Immun. 61 (1993) 1707-1714.

[21] Ménard R., Sansonetti P. J., Parsot C., J. Bacteriol. 175 (1993) 5899-5906.

[22] Ménard R., Sansonetti P. J., Parsot C., EMBO J. 13 (1994) 5293-5302.

[23] Uchiya K.-I., et al., Mol. Microbiol. 17 (1995) 241-250.

[24] Tran Van Nhieu G., Sansonetti P. J., Curr. Opin. Microbiol. 2 (1999) 51-55.

[25] Tran Van Nhieu G., Ben-Ze'ev A., Sansonetti P. J., EMBO J. 16 (1997) 2717-2729.

[26] Bourdet-Sicard R., et al., EMBO J. 18 (1999) 5853-5862.

[27] Koichi Tamano, et al., EMBO J. 19(15) (2000) 3876-3887. 